\title{
SENTINEL LYMPH NODE IN ESOPHAGEAL CANCER BEFORE NEOADJUVANT THERAPY
}

\author{
Tomáš Bohanes ${ }^{a}$, Čestmír Neorala ${ }^{a}$ René Aujeskýa, Radek Vrbaa, Jiří Kleina, Pavel Koranda ${ }^{b}$ \\ a $I^{\text {st }}$ Clinic of Surgery, Teaching Hospital Olomouc, Czech Republic \\ ${ }^{b}$ Department of Nuclear Medicine, Teaching Hospital Olomouc, Czech Republic \\ e-mail: tomas.bohanes@fnol.cz
}

Received: April 2, 2005; Accepted (with revisions): May 20, 2005

Keywords: Sentinel lymph node/Esophageal cancer/Minimally invasive surgery/Neoadjuvant therapy/Esophagus/Nanocolloid

The technique of sentinel lymph node identification and biopsy has become a new popular technique for surgeon to improve staging of malignant diseases. It may also reduce the risk of complication related to standard lymphadenectomy. The method is still in experimental phase in case of esophageal cancer. A possible complication for employment of the method in this tumor is neoadjuvant therapy.

The authors developed the technique for identifying and obtaining the sentinel lymph node in esophageal cancer using minimally invasive surgical technique before neoadjuvant therapy. The sentinel lymph node is detected using $99 \mathrm{mTc}$-labelled nanocolloid. The authors report and discuss possible difficulties of the method in the case of a patient with detected sentinel lymph node in this way.

Conclusion: It is possible to identify and obtain a sentinel lymph node before neoadjuvant therapy in esophageal cancer. On the other hand, the clinical significance and applicability of the method of sentinel lymph node still remains controversial in this kind of a tumor.

\section{INTRODUCTION}

A technique of sentinel lymph node identification and biopsy has become a new popular technique how a surgeon can improve staging of malignant diseases and also may reduce a complication risk related to the standard lymphadenectomy. This method was confirmed and accepted in breast cancer and malignant melanoma, whereas it is still in a trial phase in other solid malignancies, including esophageal cancer.

Another up-to-date method, how to treat esophageal cancer, is neoadjuvant therapy. A good response to preoperative neoadjuvant combined radio-chemotherapy was reported, including complete pathological response. However, an improvement of an overall survival remains still questionable $\mathrm{e}^{1,2,3,4}$.

Neoadjuvant therapy is a serious problem for possibility of employment of the sentinel lymph node technique in all kinds of solid malignancies. Radio-chemotherapy is supposed to alter a pattern of lymphatic drainage and that is why identification of sentinel lymph node (SLN) is usually contraindicated in these patients. The only possibility seems to be performing of this method before an application of radio-chemotherapy. Therefore, we have developed a method based on detection of SLN before the radio-chemotherapy using radiocolloid applied via esophagoscopy. Radioactivity above SLN is detected by means of a laparoscopic gamma probe and SLN is ob- tained through videolaparoscopic approach. The use of the method and possible problems are reported in a subsequent case report.

\section{CASE REPORT}

A patient S.S., 50 years old, was examined for a 3month history of dysphagia. A squamous cell cancer of the aboral esophagus in $31-38 \mathrm{~cm}$ from the incisors was found with no signs of dissemination. The patient was admitted to the $1^{\text {st }}$ Department of Surgery, Teaching Hospital Olomouc for diagnostic videolaparoscopy before neoadjuvant therapy to find possible intraabdominal dissemination. The surgery was also used for an attempt to obtain SLN.

99mTc-labelled nanocolloid $\left(\right.$ Nanocoll $\left.^{\circledR}\right)$ was applied $2 \mathrm{~h}$ before the surgery via endoscopy to the borders of the tumor. Scintigraphy was performed subsequently; it showed the only activity in the area of the stomach, which could have been SLN. Videolaparoscopy found no signs of dissemination within the abdominal cavity. Laparoscopic gamma probe detected maximal activity over the lymph node in the gastrohepatic ligament. After extirpation of the active lymph node, no high activity was detected, except in the tumor, even in the posterior mediastinum reached through the hiatus. Several other lymph nodes were found and removed during the procedure. Neither 
metastases nor micrometastases were found in the lymph nodes taken (micrometastases were detected by means of immunohistochemical identification of cytokeratins). The tumor was staged T3N0M0.

Neoadjuvant concomitant radio-chemotherapy was started two weeks later. Radiotherapy was in total dose 54 Gy, chemotherapy in 2 series of combinations Cisplatin + Fluorouracil.

The final surgery was performed three months after the first procedure. Extirpation of the esophagus and gastroplasty was performed through right-side thoracotomy. Histological examination of the esophagus found necrotic squamous cell cancer with large ulcerations. A necrotic metastasis of squamous cell cancer was found in one $8 \mathrm{~mm}$ large lymph node. The patient healed after the procedure with no complication. He has been checked-up after surgery for 6 months; he remains disease free with no signs of disease recurrence.

\section{DISCUSSION}

The importance and extent of lymphadenectomy remains questionable in esophageal cancer as for other solid malignancies. However, its significance at least for staging is undeniable ${ }^{5}$. In spite of doubts about the advantage of extended lymphadenectomy for the survival of patients, some Japanese studies have shown the benefit of such a lymphadenectomy for patients with only positivity for $\mathrm{N}$ parameter ${ }^{6,7}$. Therefore, an indication of extended lymphadenectomy should be considered carefully and the technique of SLN biopsy may be very helpful.

Employment of the principle of SLN in esophageal cancer still remains controversial. Some authors have suggested the possibility of its use because of the complexity of the drainage pattern of the esophagus through the intramural lymphatic plexi ${ }^{8,9}$. On the other hand, several studies have indicated promising opportunities of this method $^{10-14}$. Especially promising studies of cancer in Barrett's esophagus have reported good correlation between pT stage of the disease and tumor dissemination; metastases are found primarily in regional lymph nodes and distant lymph nodes are involved only in patients with multiple regional lymph node involvement ${ }^{12,13}$.

The reliability of the technique of SLN biopsy in esophageal cancer must certainly be confirmed by larger studies because it is still in the phase of pilot study. The facts stand especially for the use of the method before a neoadjuvant therapy. Controversies are well documented in our case report, i.e. especially technical aspects of obtaining of the lymph node before a radical surgery and reliability of its identification as the sentinel one.

It is clear that the only possibility of such a method is the use of SLN detection with radiocolloid and checking of the SLN site by means of scintigraphy. In spite of the fact that an experienced laparoscopic surgeon is able to get transhiatally up to the level of the azygos vein, it would be very difficult to search for SLN in the middle mediastinum, i.e. location of SLN in the abdominal cavity or in the proximity of the hiatus is necessary.
It is a question how we can call the result of the described SLN identification, i.e. if it was really successful. Detection of SLN was easy and clear; the lymph node was histologically negative. However, the final histological finding of one small nodal metastasis seems to lead to the conclusion that the study result was false negative. If we disclaim the possibility of technical failure in detection or failure of the method, we have also to admit the chance that the metastasis developed later, i.e. after the detection of SLN. The problem may be in the period of 3.5 months between SLN detection and the final surgery or at least in the 20 days between the detection and the beginning of the neoadjuvant therapy, i.e. a comparison of SLN and results of standard lymphadenectomy to assess the reliability of the method could not be performed at one time in our case.

\section{CONCLUSION}

The technique of sentinel lymph node detection and biopsy in esophageal cancer remains still a controversial issue. Subsequent trials will show if it is useful at least in the area of the distal esophagus as several studies have shown. Detection of sentinel lymph node before a neoadjuvant treatment using radiocolloid and minimally invasive surgical approach is probably possible, but subsequent study with a group of patients must recognize its difficulties and possible clinical implications, which may be slightly different than in case of the results of examination of the sentinel lymph node obtained during a radical surgical procedure.

\section{ACKNOWLEDGEMENT}

The study was supported by the grant of IGA Ministry of Health CR No. NA/7668-3

\section{REFERENCES}

1. Donington JS, Miller DL, Allen MS, Deschamps C, Nichols FC $3^{\text {rd }}$, Pairolero PC. (2003) Tumor response to induction chemoradiation: influence on survival after esophagectomy. Eur J Cardiothorac Surg 24, 631-6.

2. Malaisrie SC, Untch B, Aranha GV, Mohideen N, Hantel A, Pickleman J. (2004) Neoadjuvant chemoradiotherapy for locally advanced esophageal cancer: experience at a single institution. Arch Surg 139, 532-8.

3. Brucher BL, Stein HJ, Zimmermann F, Werner M, Sarbia M, Busch R, Dittler HJ, Molls M, Fink U, Siewert JR. (2004) Responders benefit from neoadjuvant radiochemotherapy in esophageal squamous cell carcinoma: results of a prospective phase-II trial. Eur J Surg Oncol 30, 963-71

4. Fietkau R. (2004) Definitive and neoadjuvant radiochemotherapy of squamous cell carcinoma of the oesophagus. Onkologie 27, 39-44.

5. Gervasoni JE Jr, Taneja C, Chung MA, Cady B. (2000) Biologic and clinical significance of lymphadenectomy. Surg Clin North Am 80, 1631-73.

6. Kitagawa Y, Ando N, Ozawa S, Kitajima M. (2001) Appropriate extent of lymphadenectomy in esophageal cancer. Nippon Geka Gakkai Zasshi 102, 477-83. 
7. Udagawa H, Akiyama H. (2001) Surgical treatment of esophageal cancer: Tokyo experience of the three-field technique. Dis Esophagus $14,110-14$.

8. Chin PL, Medeiros J, Schwary RE. (1999) Use of the sentinel lymph node to determine metastases of gastrointestinal malignancies: A word of caution. J Surg Oncol 71, 239-242.

9. Liebermann-Meffert D. (2001) Anatomical basis for the approach and extent of surgical treatment of esophageal cancer. Dis Esophagus 14, 81-84.

10. Kato H, Miyazaki T, Nakajima M, Takita J, Sohda M, Fukai Y. (2003) Sentinel lymph nodes with technetium-99m colloidal rhenium sulfide in patients with esophageal carcinoma. Cancer 98 , 932-39.
11. Kitagawa Y, Fujii H, Mukai M, Ando N, Kubota T, Ikeda T, Ohgami M, Watanabe M, Otani Y, Ozawa S, Hasegawa H, Furukawa T, Nakahara T, Kubo A, Kumai K, Kitajima M. (2000) The validity of the sentinel node concept in gastrointestinal cancers. Nippon Geka Gakkai Zasshi 101, 315-19.

12. Feith M, Stein HJ, Siewert JR. (2003) Pattern of lymphatic spread of Barrett's Cancer. World J Surg 27, 1052-57.

13. Kitagawa Y, Ozawa S, Fujii H, Kubo A, Kitajima M. (2003) Current status and future perspectives of sentinel node navigation surgery for esophageal cancer. Nippon Geka Gakkai Zasshi 104, 781-84.

14. Burian M, Stein HJ, Sendler A, Feith M, Siewert JR. (2004) Sentinel Lymph Node beim Magen- und Osophaguskarzinom. Chirurg 75, 756-60 